\title{
An efficient simple element for free vibration and buckling analysis of FG beam
}

\author{
Majid Yaghoobi*, Mohsen Sedaghatjo*, Reyhaneh Alizadeh* and Mohammad Karkon** \\ ${ }^{*}$ Civil Engineering and Architecture Department, Engineering Faculty, University of Torbat Heydarieh, Torbat Heydarieh, Iran. \\ *** Civil Engineering Department, Larestan Branch Islamic Azad University, Larestan, Iran.
}

Corresponding Author: majidyaghoobi@torbath.ac.ir

Submitted: 08-10-2020

Revised: 20-07-2021

Accepted: 09-08-2021

\begin{abstract}
In this paper, a simple and efficient element is proposed for the free vibration and buckling analysis of FGM beams. This element is formulating, based on Timoshenko beam theory. The assumption of constant shear strain in the element reduces the number of unknowns in addition to improving the efficiency of the new element. The performance of the new element is evaluated with the help of several benchmark tests. First, the accuracy and convergence rate of the proposed element response in the analysis of free vibration and buckling of the beam are investigated separately by exponential variations of the modulus of elasticity and density in each of the beams' thickness and length. Subsequently, the element's ability to model material variations in both longitudinal and thickness directions of the beam will be measured simultaneously. For comparison, the answers of good elements of other researchers are available in each of the numerical tests. These tests will prove the high accuracy and rapid convergence rate of the proposed element.
\end{abstract}

Keywords: Buckling; Finite element formulation; Functionally graded materials; Free vibration.

\section{INTRODUCTION}

Functionally graded materials (FGMs) are multilayer composites composed of two or more materials with different volume fractions that are made based on an approximate power or exponential relation in the desired directions. Thus, engineers can, by varying the volume fractions of the material, achieve the material ideal for the construction of high strength and stable structures, and manage the material properties. The FGM concept was first discussed in 1984 by a team of Japanese material engineers during a spacecraft project. The use of FGM materials reduces thermal stresses, residual stresses, and stress concentration factors. It also eliminates the disadvantages of laminated composites such as stress discontinuity and stress concentration as well as delamination. They also have excellent performance and resistance to cyclic mechanical and thermal loads. Thus, FGMs can be used for specific applications in various fields such as aerospace, mechanics, civil engineering, machinery, nuclear industries, the manufacture of turbine blades, etc. So far, much researches have been done on the thermodynamic, buckling, and vibration behaviors of structural elements of FGM. Euler-Bernoulli theory, Timoshenko beam theory, or first-order shear deformation theory, high-order shear deformation theory, and quasi-three-dimensional theory are some of the theories that researchers use to study the dynamic characteristics of beams.

Sankar (2001) suggested an elasticity solution for the analysis of simply supported FG beams subjected to transverse distribution load. In this work, he developed a new beam theory similar to the Euler-Bernoulli beam theory. To investigate the thermoelastic behavior of FGM structures, Chakraborty et al. (2003) proposed a new beam element based on first-order shear deformation theory. They considered stability, free vibration, and wave propagation problems to investigate the behavior of FG beams with pure metal or pure ceramic. A finite element model was proposed by Kapuria et al. (2008) for analyzing the stability and free vibration responses of layered FG beams. In this work, using Zigzag's third-order theory, effective elastic modulus for two different FGM systems with arbitrary boundary conditions is estimated and evaluated. Also, Kadoli et al. (2008) analyzed the static bending of FG beams using high-order shear deformation theory. A new beam theory different from the conventional firstorder shear deformation theories was used in 2009 to analyze the free vibration of FG beams by Sina et al. (2009). Subsequently, the free and forced vibration characteristics of the Euler-Bernoulli FG beam under a moving harmonic 
load were investigated by Şimşek and Kocatürk (2009). Şimşek (2010) studied the free vibration of a simply supported FG beam under a moving mass by using the Euler-Bernoulli, Timoshenko, and third-order shear deformation beam theories. In this study, the effects of shear deformation, various material distributions, moving mass velocity, inertia, and the centripetal effects of the moving mass on the dynamic displacements and the stresses of the beam are discussed in detail. The free vibration and static of axially loaded FG beams were investigated using the first-order shear deformation method by Nguyen et al. (2013). In 2017, he also applied the Timoshenko beam model and finite element study for dynamic responses of bi-directional FG beams under moving load(Nguyen et al. 2017). Nowadays, the study of structures made of FGMs with the use of efficient finite elements has attracted the attention of many researchers. Introducing stress equilibrium conditions, Li et al. (2019) developed a new highorder shear deformation theory. He presented new deformable mixed beam elements based on the new proposed theory for the detailed analysis of FG sandwich beams. Nguyen et al. (2019) developed an efficient two-node beam element based on the quasi-3D beam theory and mixed formulation to study the static bending of FG beams. Subsequently, Soltani et al. (2019) investigated the lateral buckling of simply supported non-prismatic I-beams with axially varying materials by using a new finite element model. A five-node beam finite element has been proposed by Aria et al. (2019) to analyze the thermo-elastic behavior of porous FG nanobeams. They used the non-local elasticity theory to incorporate the size-dependent behavior of nanobeams. Recently, (Yaghoobi et al. 2021) evaluated the asymmetric effect of the cross-section on the free vibration and bending analysis of FG sandwich beams. Also, a pair of functionally graded nano-wire-based tweezers with linearly varying diameter has been proposed by Yaghoobi and Koochi (2021) to enhance the nano-tweezers' operating range.

In this paper, a simple and efficient element is proposed for the free vibration and buckling analysis of FGM beams. The proposed element is formulated based on Timoshenko's theory and assuming shear strain constant. In formulation, the third-order function for the displacement field along the element thickness is used. Second-order functions are also utilized for longitudinal displacement and rotation fields. The efficiency of the proposed element in free vibration and buckling analysis is evaluated by varying the material properties along the thickness and length separately in several tests. To prove the rapid convergence, efficiency, and accuracy of the proposed element, the answers of other good elements of the researchers are also available.

\section{ELEMENT FORMULATION}

In this section, the formulation of the new beam element for free vibration analysis and buckling of FGM beams is presented. First, shape functions are calculated. Then, the governing equation of free vibration and buckling of beams will be established by calculating the matrices of stiffness, mass, and geometrical stiffness.

\section{SHAPE FUNCTIONS}

Figure 1 shows the beam element geometry with three nodes and seven degrees of freedom. This element has length $l$ and rectangular cross-section with width $b$ and height $h$. The origin of the $x$-coordinate axis is located the node $i$. The $x$-axis represents the longitudinal direction of the beam. To simplify the formulation, the dimensionless parameter $s$ is defined as a new coordinate. The origin of the $s$ coordinates is also shown in Figure 1. The value of the parameter $s$ on the nodes $i, j$, and $k$ are $-1,0$, and 1 , respectively. The relationship between the coordinate $x$ and $s$ comes in Equation (1). The $z$-axis is considered positive along the thickness and upward. The vertical displacement at each node is considered positive along the $z$-axis.

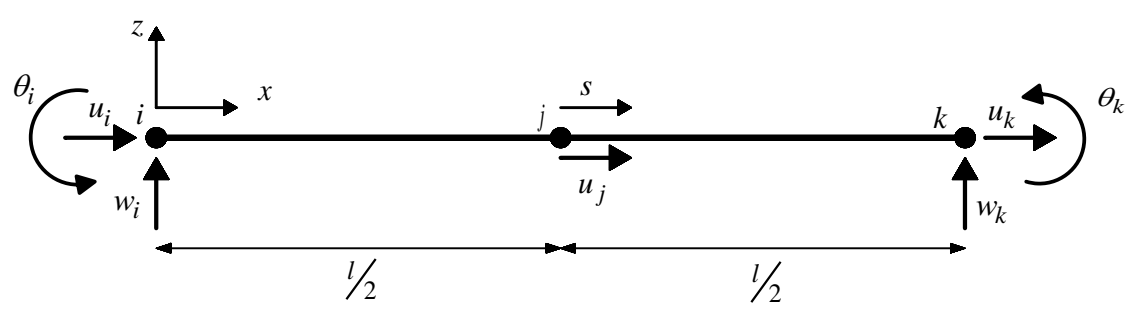

Figure 1. The geometry of proposed element. 
For the vertical displacement field, $w$, uses the third-order function. Also, a second-order polynomial for the rotation field, $\boldsymbol{\theta}$, is assumed. Equations (2) and (3) represent these fields. $w_{i}$ and $w_{k}$ shows the vertical displacement of the nodes $i$ and $k$, respectively. Also, the rotations in nodes $i$ and $k$ are determined by the parameters $\theta_{i}$ and $\theta_{k}$, respectively. Besides, the parameters $\alpha_{\circ}, \beta_{\circ}$ and $\beta_{1}$ are used to define the unknowns of the fields.

$$
\begin{aligned}
& s=\frac{2 x}{l}-1 \\
& w=\frac{w_{i}}{2}(1-s)+\frac{w_{k}}{2}(1+s)+\beta_{\circ} l\left(1-s^{2}\right)+\beta_{1} l s\left(1-s^{2}\right) \\
& \theta=\frac{\theta_{i}}{2}(1-s)+\frac{\theta_{k}}{2}(1+s)+\alpha_{\circ}\left(1-s^{2}\right)
\end{aligned}
$$

The second-order polynomial is exploited for the longitudinal displacement field along $s$. Equation (4) shows the equation of this field. Also, Equation (5) makes the element longitudinal displacement field available. Using displacement fields along the longitudinal and vertical directions of the beam, the shear strain function is calculated as Equation (6). Assuming a constant shear strain, the value of each of the unknown parameters of the vertical displacement and rotation fields becomes available. The constant value of the shear strain is represented by $\gamma_{0}$. Consequently, by replacing the rotation and vertical displacement functions in Equation (6), the element shear strain function is established. Assuming the shear strain of the element is equal to a constant value of $\gamma_{0}$, Equation (7) is obtained.

$$
\begin{aligned}
& u=\frac{s(s-1)}{2} u_{i}-\left(s^{2}-1\right) u_{j}+\frac{s(s+1)}{2} u_{k} \\
& U(s, z, t)=u(s, t)-z \theta(s, t) \\
& \gamma_{s z}=\frac{\partial U}{\partial z}+\frac{2}{l} \frac{\partial w}{\partial s}=\frac{2}{l} \frac{\partial w}{\partial s}-\theta=\frac{2}{l} w_{, s}-\theta \\
& \gamma_{\circ}=\frac{2}{l}\left(-\frac{w_{i}}{2}+\frac{w_{k}}{2}-2 \beta_{\circ} l s+\beta_{1} l-3 \beta_{1} l^{2}\right)-\theta_{i}\left(\frac{1-s}{2}\right)-\theta_{k}\left(\frac{1+s}{2}\right)-\alpha_{\circ}\left(1-s^{2}\right)
\end{aligned}
$$

The parameters $u$ and $\theta$ in the above equations represent the horizontal displacement field and the rotational field of the beam, respectively. It is assumed that the shear strain must be constant throughout the beam. In other words, Equation (7) will be independent of the parameter s. Accordingly, the following equations are available to find unknown parameters of the fields. Also, Equation (11) is used to simplify the relations.

$$
\begin{aligned}
& \alpha_{\circ}=-\frac{3}{2}\left(\gamma_{\circ}-\frac{1}{2} \Gamma\right) \\
& \beta_{\circ}=\frac{1}{8}\left(\theta_{i}-\theta_{k}\right) \\
& \beta_{1}=\frac{1}{6} \alpha_{\circ}
\end{aligned}
$$




$$
\Gamma=\frac{2}{l}\left(w_{k}-w_{i}\right)-\left(\theta_{i}+\theta_{k}\right)
$$

The principle of minimizing strain energy is used to find the $\gamma_{0}$ value. The element strain energy in Equation (12) is shown. $\sigma_{x x}$ and $\tau_{x z}$, represent normal and shear stresses, respectively. Also, the normal and shear strains are defined by $\varepsilon_{x x}$ and $\gamma_{x z}$, respectively. Relationships of stresses with their strains are given in Equations (13) and (14). Also, the normal strain is calculated based on Equation (15) in terms of the longitudinal displacement field of the beam. The parameters $E_{e}, G_{e}$, and $f_{s}$, respectively, determine the modulus of elasticity, shear modulus, and shear correction coefficient of the cross-section. For rectangular cross-section, $f_{s}$ has a value of $5 / 6$ . The shear modulus is obtained by Equation (16) in terms of the modulus of elasticity. $v$ is the Poisson's ratio.

$$
\begin{aligned}
& U=\frac{1}{2} \int_{0}^{l} \int_{A}\left(\sigma_{x x} \varepsilon_{x x}+\tau_{x z} \gamma_{x z}\right) d A d x \\
& \sigma_{x x}=E_{e} \varepsilon_{x x} \\
& \tau_{x z}=f_{s} G_{e} \gamma_{x z} \\
& \varepsilon_{x x}=\frac{2}{l} \frac{\partial U}{\partial s}=\frac{2}{l}\left(\frac{\partial u}{\partial s}-z \frac{\partial \theta}{\partial s}\right) \\
& G_{e}=\frac{E_{e}}{2(1+v)}
\end{aligned}
$$

This study assumes that the elasticity modulus $E_{e}$ and mass density $\rho_{e}$ vary based on the power relation proportional to $k$. Equation (17) shows the variation of these parameters only through the thickness, $z$. Also, the state of changing the material properties along the length $x$ is shown by Equation (18). Equation (19) introduces changes in material properties in both longitudinal and thick directions. The parameter $P_{e}$ is used to represent the pattern of change in the material properties. $P_{u}$ and $P_{d}$, respectively, represent the material properties at the top and bottom of the beam. Also, the characteristics of the material on the right and left of the beam are described by $P_{r}$ and $P_{l}$, respectively. The three-dimensional geometry of the beam element is shown in Figure 2.

$$
\begin{aligned}
& P_{e}(z)=P_{z}=\left(P_{u}-P_{d}\right)\left(\frac{z}{h}+\frac{1}{2}\right)^{k_{z}}+P_{d} \\
& P_{e}(x)=P_{x}=\left(P_{l}-P_{r}\right)\left(1-\frac{x}{l}\right)^{k_{x}}+P_{r} \\
& P_{e}(x, z)=P_{x, z}=P_{m} e^{k_{x}\left(1-\frac{x}{l}\right)+k_{z}\left(\frac{z}{h}+\frac{1}{2}\right)}
\end{aligned}
$$




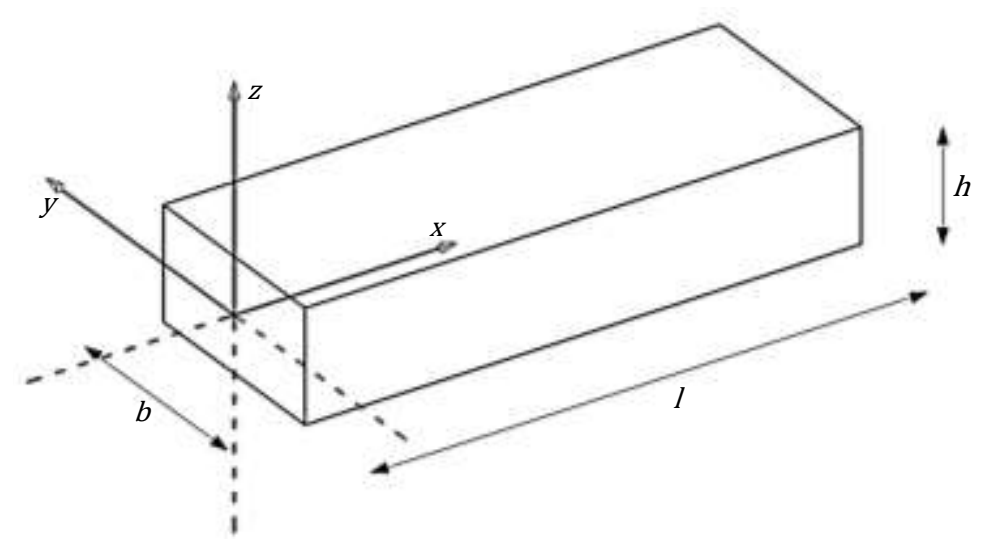

Figure 2. Three-dimensional coordinate system of the beam element.

To calculate Equation (12), after writing the stress and strain functions in terms of longitudinal displacement, vertical displacement, and rotation fields, first the integral is performed on the surface. In this way, the strain energy relation is given as Equation (20). In this equation, the index $s$ in the expressions $u_{, s}$ and $\theta_{, s}$ represent the derivative of these expressions relative to $s$. The parameters $A_{0}, A_{1}, A_{2}$ and $B_{0}$ are introduced as follows.

$$
\begin{aligned}
& U=\frac{1}{2} \int_{0}^{l}\left[\frac{4}{l^{2}} A_{0}\left(u_{, s}\right)^{2}-\frac{8}{l^{2}} A_{1}\left(u_{, s}\right)\left(\theta_{, s}\right)+\frac{4}{l^{2}} A_{2}\left(\theta_{, s}\right)^{2}+B_{0}\left(\gamma_{0}\right)^{2}\right] d s \\
& {\left[A_{0}, A_{1}, A_{2}\right]=\int_{A} E_{e}\left[1, z, z^{2}\right] d A} \\
& B_{0}=\int_{A} f_{s} G_{e} d A
\end{aligned}
$$

By solving the integral of Equation (20), the strain energy of the element becomes available. The parameter $\gamma_{\circ}$ is obtained by minimizing the strain energy with respect to $\gamma_{\circ}$ as Equation (23). The $\lambda$ and $\delta$ parameters are used for simplification. The parameters $A_{11}, A_{12}, A_{21}, A_{22}$, and $B_{00}$ are available as follows.

$$
\begin{aligned}
& \gamma_{\circ}=\delta-\lambda\left(A_{21}\left(\theta_{k}-\theta_{i}\right)+2 A_{12}\left(-u_{i}+2 u_{j}-u_{k}\right)+A_{11}\left(u_{i}-u_{k}\right)\right)=\mathbf{N}_{\gamma_{\circ}} \mathbf{D} \\
& \delta=3 A_{22} \Gamma \lambda, \quad \lambda=\frac{6}{36 A_{22}+B_{00} l^{2}} \\
& {\left[A_{11}, A_{12}\right]=\int_{-1}^{1} A_{1}\left[s, s^{2}\right] d s} \\
& {\left[A_{21}, A_{22}\right]=\int_{-1}^{1} A_{2}\left[s, s^{2}\right] d s}
\end{aligned}
$$




$$
B_{00}=\int_{-1}^{1} B_{0} d s
$$

The matrix of the element shape functions shows the relationship between the displacement and rotation fields with the nodal displacement vector as Equation (28). The nodal displacement vector, $\mathbf{D}$, comes from Equation (29). By computing, the unknowns $\alpha_{0}, \beta_{\circ}, \beta_{1}$, and $\gamma_{0}$, the element shape functions become available as Appendix(A1).

$$
\begin{aligned}
& \left\{\begin{array}{l}
u \\
w \\
\theta
\end{array}\right\}=\left[\begin{array}{l}
\mathbf{N}_{u} \\
\mathbf{N}_{w} \\
\mathbf{N}_{\theta}
\end{array}\right] \mathbf{D} \\
& \mathbf{D}^{T}=\left[\begin{array}{lllllll}
u_{i} & w_{i} & \theta_{i} & u_{j} & u_{k} & w_{k} & \theta_{k}
\end{array}\right]
\end{aligned}
$$

\section{FREE VIBRATION AND BUCKLING}

The element rotation and displacement fields can be written in terms of nodal displacement vectors by obtaining the shape functions. Accordingly, the matrix form of the strain energy is given as an Equation (30). Also, by minimizing energy relative to nodal displacements, the stiffness matrix, $\mathbf{K}$, is calculated.

$$
\begin{aligned}
& U=\frac{1}{2} \mathbf{D}^{T}\left(\int_{0}^{l}\left[\frac{4}{l^{2}} A_{0} \mathbf{N}_{u, s}^{T} \mathbf{N}_{u, s}-\frac{8}{l^{2}} A_{1} \mathbf{N}_{u, s}^{T} \mathbf{N}_{\theta, s}+\frac{4}{l^{2}} A_{2} \mathbf{N}_{\theta, s}^{T} \mathbf{N}_{\theta, s}+B_{0} \mathbf{N}_{\gamma_{0}}^{T} \mathbf{N}_{\gamma_{o}}\right] d s\right) \mathbf{D} \\
& \mathbf{K}=\int_{0}^{l}\left[\frac{4}{l^{2}} A_{0} \mathbf{N}_{u, s}^{T} \mathbf{N}_{u, s}-\frac{8}{l^{2}} A_{1} \mathbf{N}_{u, s}^{T} \mathbf{N}_{\theta, s}+\frac{4}{l^{2}} A_{2} \mathbf{N}_{\theta, s}^{T} \mathbf{N}_{\theta, s}+B_{0} \mathbf{N}_{\gamma_{0}}^{T} \mathbf{N}_{\gamma_{o}}\right] d s
\end{aligned}
$$

Furthermore, kinetic energy is calculated from the Equation (32). The parameter $\rho_{e}$ represents the mass density. Using the parameters calculated in Equation (34) we can simplify the kinetic equation of the Equation (33). Based on Hamilton's principle, the mass matrix is calculated as Equation (35).

$$
\begin{aligned}
& T=\frac{1}{2} \int_{0}^{l} \int_{A} \rho_{e}\left(\dot{U}_{(s, z, t)}^{2}+\dot{w}_{(s, z, t)}^{2}\right) d A d s \\
& T=\frac{1}{2} \int_{0}^{l}\left[I_{0}(\dot{u})^{2}-2 I_{1}(\dot{u})(\dot{\theta})+I_{2}(\dot{\theta})^{2}+I_{0}(\dot{w})^{2}\right] d s \\
& {\left[I_{0}, I_{1}, I_{2}\right]=\int_{A} \rho_{e}\left[1, z, z^{2}\right] d A} \\
& \mathbf{M}=\int_{0}^{l}\left[I_{0} \mathbf{N}_{u}^{T} \mathbf{N}_{u}-2 I_{1} \mathbf{N}_{u}^{T} \mathbf{N}_{\theta}+I_{2} \mathbf{N}_{\theta}^{T} \mathbf{N}_{\theta}+I_{0} \mathbf{N}_{w}^{T} \mathbf{N}_{w}\right] d s
\end{aligned}
$$


The governing buckling equation of beam is established based on the neutral equilibrium concept. Based on Figure 3, neglecting the small axial shortening prior to buckling, the vertical distance $\Delta$, due to the flexural deflection is calculated as:

$$
\Delta=\frac{1}{2} \int_{0}^{l}\left(\frac{d w}{d x}\right)^{2} d x
$$

Hence, the change in potential energy of the critical load is obtained as below shape:

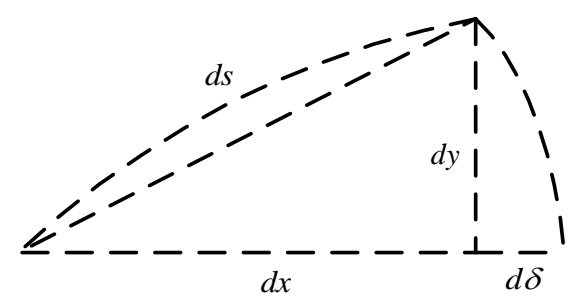

Figure 3. The geometry of the element of buckled beam.

$$
\Delta W=P \Delta=\frac{1}{2} \int_{0}^{l} P\left(w_{, s}\right)^{2} d s
$$

In Equation (37), the term $w_{, s}$ means the derivative of the displacement field in the vertical direction relative to $s$. Therefore, the geometrical stiffness matrix is available as:

$$
\mathbf{K}_{\mathrm{g}}=\int_{0}^{l} \frac{4}{l^{2}} \mathbf{N}_{w, s}^{T} \mathbf{N}_{w, s} d x
$$

Equation (39) illustrates the governing equation of the element. For free vibration mode without axial force, the matrix $\mathbf{K}_{g}$ is ignored. In this case, by substituting $\mathbf{D}=\mathbf{D}_{\mathbf{o}} e^{i \omega t}$, Equation (40) is obtained. The $\omega$ denotes natural frequencies. The eigenvalues of Equation (40) are the natural frequencies of the beam. By replacing $\mathbf{D}=\mathbf{D}_{\mathbf{0}} e^{\lambda x}$ and ignoring the matrix $\mathbf{M}$, the governing equation of buckling becomes available as an Equation (41). The least eigenvalues of this relation indicate the buckling load value.

$$
\begin{aligned}
& \mathbf{M} \ddot{\mathbf{D}}+\left(\mathbf{K}-P \cdot \mathbf{K}_{g}\right) \mathbf{D}=\mathbf{0} \\
& \left(\mathbf{K}-\omega^{2} \cdot \mathbf{M}\right) \mathbf{D}_{\mathbf{o}}=\mathbf{0} \\
& \left(\mathbf{K}-P \cdot \mathbf{K}_{g}\right) \mathbf{D}_{\mathbf{o}}=\mathbf{0}
\end{aligned}
$$

\section{NUMERICAL TESTS}

In this section, the efficiency of the element is evaluated by applying the proposed element and comparing it with the good ones of others in the free vibration and buckling analysis of FGM beams. In FGM beams, it is assumed that the elasticity modulus $E_{e}$ and mass density $\rho_{e}$ vary based on the power law. The benchmark tests with changes in these parameters along the thickness are given in section 3-1. Section 3-2 includes numerical tests, with changes in the material properties along the beam length.

In different support conditions, the term $P-P$ indicates that there are simple supports on both sides of the beam. The clamped support conditions on both sides of the beam show with $C-C$. The $C-F$ also represented the cantilever beam. 
The calculation of the eigenvalues of the stiffness and mass matrices, or in other words the calculation of the determinants of Equation (40), provides the values of the natural frequencies. Other researchers have used nondimensional natural frequency in free vibration analysis to present their results. Therefore, to compare the results in each benchmark test, the non-dimensional natural frequencies of the structure for the proposed element will be calculated using the relation provided in the title of the benchmark dependent table.

\section{CHANGING THE PROPERTIES OF THE MATERIALS ALONG THE THICKNESS}

In this section, it is assumed that the properties of material change only through-thickness. How to change the material properties in the thickness of the beam was shown as a power relation in terms of $k_{z}$ in Equation (17). In the case of using aluminum at the bottom and aluminum oxide at the top of the beam, Figure 4 shows the changes in elasticity modulus and mass density of the beam thickness. The characteristics of aluminum, aluminum oxide, and steel are presented in Table 1 . The $v_{f}$ and $v_{b}$ represent the magnitude of the Poisson's ratio used in free vibration and buckling problems, respectively.
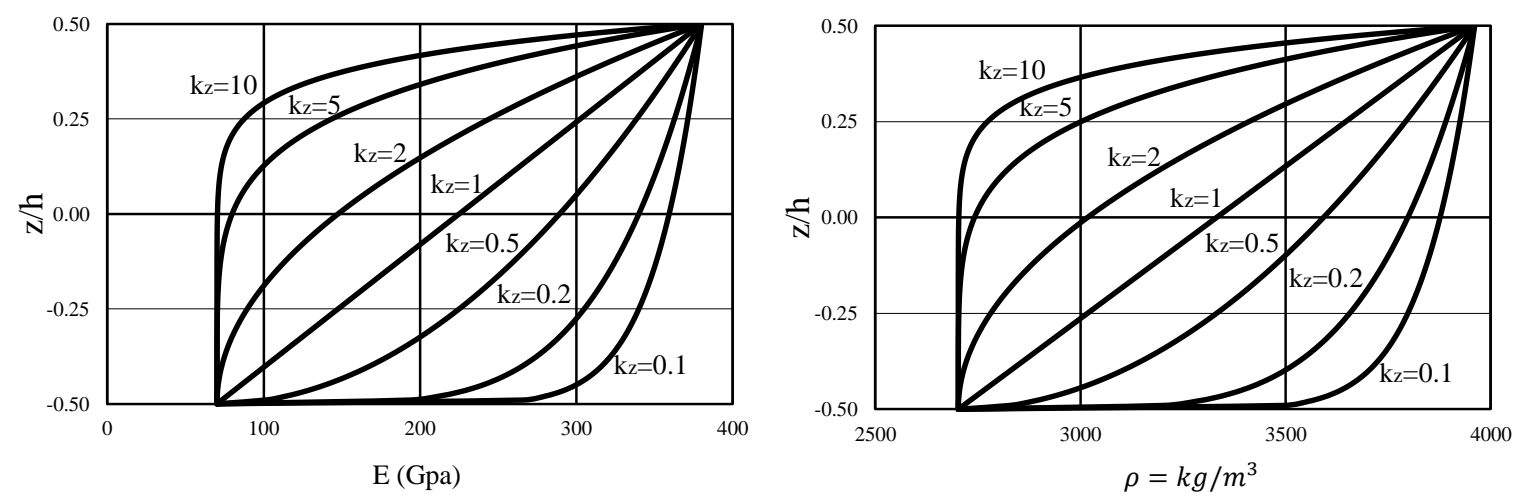

Figure 4. Changes of elastic modulus and mass density along the beam thickness.

Table 1. Physical properties of materials.

\begin{tabular}{ccccc}
\hline Matrial & $\boldsymbol{E}(\mathrm{Gpa})$ & $\boldsymbol{\rho}\left(\mathrm{kg} / \mathrm{m}^{3}\right)$ & $\boldsymbol{U}_{\boldsymbol{f}}$ & $\boldsymbol{U}_{\boldsymbol{b}}$ \\
\hline $\mathrm{Al}$ & 70 & 2702 & 0.3 & 0.23 \\
$\mathrm{Al}_{2} \mathrm{O}_{3}$ & 380 & 3960 & 0.3 & 0.23 \\
Steel & 210 & 7850 & 0.3 & 0.23 \\
\hline
\end{tabular}

\section{CONVERGENCE RATE}

In order to show the rapid convergence rate and high accuracy of the proposed element, the buckling and free vibration analysis of an FG beam is analyzed with various boundary conditions with a length to thickness ratio of 5 and $k_{z}=1$. To this end, the suggested element is used for free vibration and buckling analysis of $P-P, C-C$, and $C-F$ conditions with several meshes, and its responses are compared with the good results of other researchers. 
Table 2 lists the responses of dimensionless frequency $\bar{\omega}$. Also, the dimensionless critical load $\bar{N}$ of the mentioned beam with various boundary conditions is presented in Table 2 . It should be noted that the $\bar{\omega}$ and $\bar{N}_{c r}$ parameters are available in section 3-1 as follows:

$$
\begin{aligned}
& \bar{\omega}=\frac{\omega l^{2}}{h} \sqrt{\frac{\rho_{d}}{E_{d}}} \\
& \bar{N}_{c r}=N_{c r} \frac{12 l^{2}}{E_{d} h^{3}}
\end{aligned}
$$

Evaluation of these tables shows the high accuracy and rapid convergence rate of the proposed element in the analysis of FG beams with different boundary conditions. Kahya and Turan (2017) responses are available for comparison by applying 20 elements and each of their element has four nodes and nine degrees of freedom. The results of Simsek, Li, and Batra for dimensionless natural frequencies and normalized critical load are also given in Table 2.

Table 2. Convergence of the proposed element for FGM beam with different boundary conditions

\begin{tabular}{|c|c|c|c|}
\hline Number of Elements & $\mathrm{C}-\mathrm{C}$ & $\mathbf{P}-\mathbf{P}$ & C-F \\
\hline \multicolumn{4}{|c|}{ Normalized fundamental frequency $\left(\bar{\omega}=\frac{\omega l^{2}}{h} \sqrt{\frac{\rho_{d}}{E_{d}}}\right)$} \\
\hline 2 & 8.19982 & 4.01342 & 1.46484 \\
\hline 4 & 7.96681 & 3.97921 & 1.46318 \\
\hline 6 & 7.92796 & 3.97437 & 1.46294 \\
\hline 8 & 7.91530 & 3.97279 & 1.46286 \\
\hline 10 & 7.90960 & 3.97208 & 1.46282 \\
\hline 12 & 7.90656 & 3.97170 & 1.46280 \\
\hline 14 & 7.90473 & 3.97147 & 1.46279 \\
\hline 16 & 7.90356 & 3.97133 & 1.46278 \\
\hline 18 & 7.90275 & 3.97123 & 1.46278 \\
\hline 20 & 7.90218 & 3.97115 & 1.46277 \\
\hline Kahya and Turan (2017) & 7.89921 & 3.97085 & 1.46276 \\
\hline Şimşek (2010) & 7.92529 & 3.99023 & 1.46300 \\
\hline Normalized buckling load & \multicolumn{2}{|c|}{$\overline{\left(\bar{N}_{c r}=N_{c r} \frac{12 l^{2}}{E_{d} h^{3}}\right)}$} & \\
\hline
\end{tabular}

$$
\left(l / h=5, k_{z}=1\right) \text {. }
$$




\begin{tabular}{clll}
4 & 83.79227 & 24.78467 & 6.54447 \\
6 & 81.91009 & 24.72828 & 6.54339 \\
8 & 81.45277 & 24.70983 & 6.54305 \\
10 & 80.99544 & 24.70152 & 6.54289 \\
12 & 80.84200 & 24.69707 & 6.54281 \\
14 & 80.75003 & 24.69440 & 6.54276 \\
16 & 80.69055 & 24.69268 & 6.54273 \\
18 & 80.64988 & 24.69150 & 6.54270 \\
20 & 80.62084 & 24.69066 & 6.54269 \\
Kahya and Turan (2017) & 80.49833 & 24.68713 & 6.54262 \\
Li and Batra (2013) & 80.49800 & 24.68700 & 6.60020 \\
\hline
\end{tabular}

\section{Free vibration and buckling analysis under different boundary conditions}

In this section, to show the high accuracy of the proposed element in the study of FGM beams by varying the properties of the material along the thickness, beams with different boundary conditions and different powerlaw exponents of FGM are investigated. For this purpose, free vibration analysis of simply supported FG beams $P$ $P$, beams with clamped supports $C$ - $C$, and cantilever beam $C-F$ is performed. It should be noted that, 20 elements were used for analyzing benchmark tests. The ratio of length to thickness is assumed to be equal to five for Tables 3 and 4 . By performing the analysis, the dimensionless frequency $\bar{\omega}$ and critical load $\bar{N}_{c r}$ responses for the proposed element, along with the results of other researchers, are presented in Tables 3 and 4, respectively. By examining the responses listed in the tables, it can be seen that the proposed element has high accuracy in analyzing different FGM beams for all types of boundary conditions.

Table 3. Non-dimensional frequency $\left(\bar{\omega}=\frac{\omega l^{2}}{h} \sqrt{\frac{\rho_{d}}{E_{d}}}\right.$ ) for FGM beam with different boundary conditions.

\begin{tabular}{|c|c|c|c|c|c|c|c|c|}
\hline B.C & Element & $k_{z}=0$ & $k_{z}=0.5$ & $k_{z}=1$ & $k_{z}=2$ & $k_{z}=5$ & $k_{z}=10$ & $k_{z}=\infty$ \\
\hline \multirow[t]{5}{*}{$\mathrm{C}-\mathrm{C}$} & Present & 10.09122 & 8.74527 & 7.96501 & 7.24766 & 6.70571 & 6.37988 & 5.24332 \\
\hline & Kahya and Turan (2017) & 10.08647 & 8.75479 & 7.98414 & 7.27155 & 6.71481 & 6.37413 & 5.24085 \\
\hline & Şimşek (2010) & 10.0705 & 8.74674 & 7.95034 & 7.17674 & 6.49349 & 6.16515 & 5.23254 \\
\hline & Nguyen et al. (2015) & 10.0726 & 8.7463 & 7.9518 & 7.1776 & 6.4929 & 6.1658 & - \\
\hline & Barretta et al. (2015) & 10.0678 & 8.7457 & 7.9522 & 7.1801 & 6.4961 & 6.1662 & - \\
\hline
\end{tabular}




\begin{tabular}{|c|c|c|c|c|c|c|c|c|}
\hline & .Barretta et al. (2016) & 10.1851 & 8.8641 & 8.077 & 7.3039 & 6.596 & 6.2475 & - \\
\hline \multirow[t]{6}{*}{ P-P } & Present & 5.16521 & 4.40851 & 3.97901 & 3.61202 & 3.41047 & 3.30509 & 2.68380 \\
\hline & .Kahya and Turan (2017) & 5.22193 & 4.46926 & 4.04967 & 3.6936 & 3.48818 & 3.36434 & 2.71328 \\
\hline & Şimşek (2010) & 5.15274 & 4.41108 & 3.99042 & 3.62643 & 3.4012 & 3.2816 & 2.67732 \\
\hline & Nguyen et al. (2015) & 5.1528 & 4.4102 & 3.9904 & 3.6264 & 3.4009 & 3.2815 & - \\
\hline & Barretta et al. (2015) & 5.1528 & 4.4019 & 3.9716 & 3.5979 & 3.3743 & 3.2653 & - \\
\hline & Barretta et al. (2016) & 5.1618 & 4.424 & 4.0079 & 3.6442 & 3.4133 & 3.2903 & - \\
\hline \multirow[t]{3}{*}{$\mathrm{C}-\mathrm{F}$} & Present & 1.89674 & 1.61870 & 1.46427 & 1.33493 & 1.26578 & 1.22542 & 0.98553 \\
\hline & Kahya and Turan (2017) & 1.90772 & 1.62865 & 1.47394 & 1.34469 & 1.27515 & 1.26363 & 0.99124 \\
\hline & Şimşek (2010) & 1.89523 & 1.61817 & 1.46328 & 1.33254 & 1.25916 & 1.21834 & 0.98474 \\
\hline & Nguyen et al. (2015) & 1.8957 & 1.6182 & 1.4636 & 1.3328 & 1.2594 & 1.2187 & - \\
\hline & Barretta et al. (2015) & 1.8952 & 1.618 & 1.4633 & 1.3326 & 1.2592 & 1.2184 & - \\
\hline & Barretta et al. (2016) & 1.9055 & 1.6313 & 1.4804 & 1.3524 & 1.2763 & 1.2308 & - \\
\hline
\end{tabular}

Table 4. Non-dimensional buckling load $\left(\bar{N}_{c r}=N_{c r} \frac{12 l^{2}}{E_{d} h^{3}}\right)$ for FGM beam with different boundary conditions.

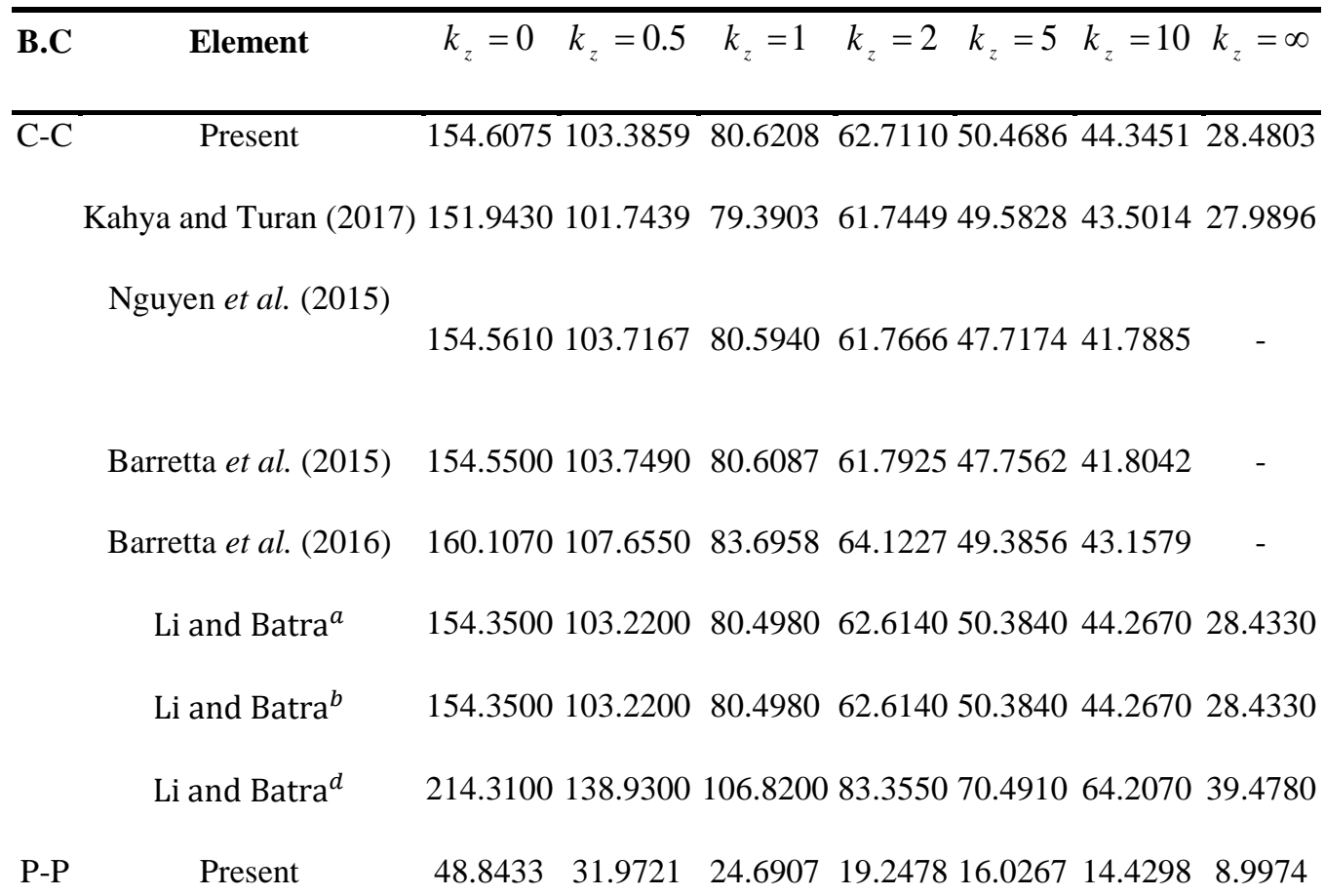

Kahya and Turan (2017) $48.5907 \quad 31.8238 \quad 24.5815 \quad 19.1617 \quad 15.9417 \quad 14.3445 \quad 8.9510$

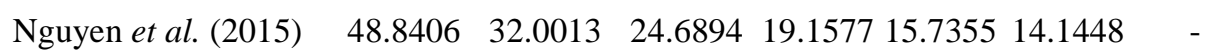




\begin{tabular}{|c|c|c|c|c|c|c|}
\hline Barretta et al. (2015) & 48.8401 & 32.0094 & 24.6911 & 19.160515 .7400 & 14.1468 & - \\
\hline Barretta et al. (2016) & 49.5901 & 32.5867 & 25.2116 & 19.612416 .0842 & 14.4116 & - \\
\hline $\mathrm{Li}$ and Batra ${ }^{a}$ & 48.8350 & 31.9670 & 24.6870 & 19.245016 .0240 & 14.4270 & 8.9959 \\
\hline $\mathrm{Li}$ and Batra ${ }^{b}$ & 48.8350 & 31.9670 & 24.6870 & 19.245016 .0240 & 14.4270 & 8.9959 \\
\hline Li and Batra ${ }^{d}$ & 53.5780 & 34.7310 & 26.7050 & 20.838017 .6230 & 16.0520 & 9.8696 \\
\hline Present & 13.0771 & 8.4992 & 6.5427 & $5.1041 \quad 4.2985$ & 3.9031 & 2.4089 \\
\hline Kahya and Turan (2017) & 13.0594 & 8.4899 & 6.5352 & $5.0981 \quad 4.2926$ & 3.8970 & 2.4057 \\
\hline Nguyen et al. (2015) & 13.0771 & 8.5000 & 6.5427 & $5.0977 \quad 4.2772$ & 3.8820 & - \\
\hline Barretta et al. (2015) & 13.0771 & 8.5020 & 6.5428 & $5.0979 \quad 4.2776$ & 3.8821 & - \\
\hline Barretta et al. (2016) & 13.0993 & 8.5469 & 6.6067 & $5.1680 \quad 4.3290$ & 3.9121 & - \\
\hline $\mathrm{Li}$ and Batra ${ }^{a}$ & 13.2130 & 8.5782 & 6.6002 & $5.1495 \quad 4.3445$ & 3.9501 & 2.4340 \\
\hline Li and Batra ${ }^{c}$ & 13.2130 & 8.5782 & 6.6002 & $5.1495 \quad 4.3445$ & 3.9502 & 2.4340 \\
\hline Li and Batra ${ }^{d}$ & 13.3940 & 8.6829 & 6.6763 & $5.2097 \quad 4.4057$ & 4.0129 & 2.4674 \\
\hline
\end{tabular}

\section{Natural frequencies of higher modes}

To demonstrate the efficiency of the proposed element in the calculation of the frequency for the higher modes of the FGM beam, a beam made of steel at the top and aluminum at the bottom is analyzed with simple supports. The desired length and thickness of the beam are 0.5 and 0.125 . The natural frequencies of the first five modes are calculated. The properties of the FGM material used for the beam are summarized in Table 1. By performing the free vibration analysis, the proposed element responses, along with those of other researchers, are listed in Table 5. This table proved the high accuracy of the suggested element even for frequencies of higher-order modes.

Table 5. The first five natural frequency $(\mathrm{rad} / \mathrm{s})$ of free vibration for FGM beam.

\begin{tabular}{|c|c|c|c|c|c|c|c|c|c|c|}
\hline \multirow[b]{2}{*}{ Mode } & \multicolumn{3}{|c|}{$\operatorname{Steel}\left(k_{z}=\infty\right)$} & \multicolumn{4}{|c|}{$\boldsymbol{F G M}\left(k_{z}=1\right)$} & \multicolumn{3}{|c|}{$\mathbf{A} \mathbf{l}\left(k_{z}=0\right)$} \\
\hline & $\begin{array}{c}\text { Kahya } \\
\text { and } \\
\text { Turan } \\
(2017)\end{array}$ & Li (2008) & Present & $\begin{array}{l}\text { Kahya } \\
\text { and } \\
\text { Turan } \\
(2017)\end{array}$ & Şimşek (2010) & Li (2008) & Present & $\begin{array}{l}\text { Kahya } \\
\text { and } \\
\text { Turan } \\
(2017)\end{array}$ & Li (2008) & Present \\
\hline 1 & 6858.23 & 6728.89 & 6600.23 & 6574.81 & 6443.78 & 6457.93 & 6420.20 & 6742.83 & 6615.66 & 6713.19 \\
\hline 2 & 23178.91 & 22279.03 & 21793.93 & 22456.85 & 21493.99 & 21603.18 & 21617.26 & 22788.88 & 21904.14 & 22166.92 \\
\hline 3 & 42917.53 & 41094.04 & 40205.72 & 41942.82 & 39909.87 & 40145.42 & 39878.00 & 42195.37 & 40402.57 & 40893.83 \\
\hline 4 & 63325 & 60889.98 & 59772.11 & 62243.73 & 59509.8 & 59779.01 & 59730.10 & 62259.45 & 59865.4 & 60795.09 \\
\hline 5 & 83630.93 & 80895.78 & 79908.85 & 82505.87 & 79589.32 & 79686.16 & 80472.08 & 82223.7 & 79534.57 & 81276.46 \\
\hline
\end{tabular}




\section{Free vibration analysis for different ratios of elasticity modulus}

In the following, the free vibration analysis of FGM beams with different elasticity modulus ratios will be evaluated. In this study, a simply supported beam with length to thickness ratios of 20 and 100 is considered. Nondimensional natural frequency responses of the proposed element for the first mode are listed in Table 6. Also, the response of other researchers' good elements is available for comparison. The high efficiency of the proposed element for different elasticity modulus ratios, length to thickness ratios, and $k_{z}$ parameters in this test are evident. The dimensionless natural frequency of $\lambda$, for section $3-1$, is defined in the following relation:

Table 6. Non-dimensional first natural frequency $\left(\lambda=\omega l^{2} \sqrt{\frac{\rho_{d} A}{E_{d} I}}\right)$ for FGM beam.

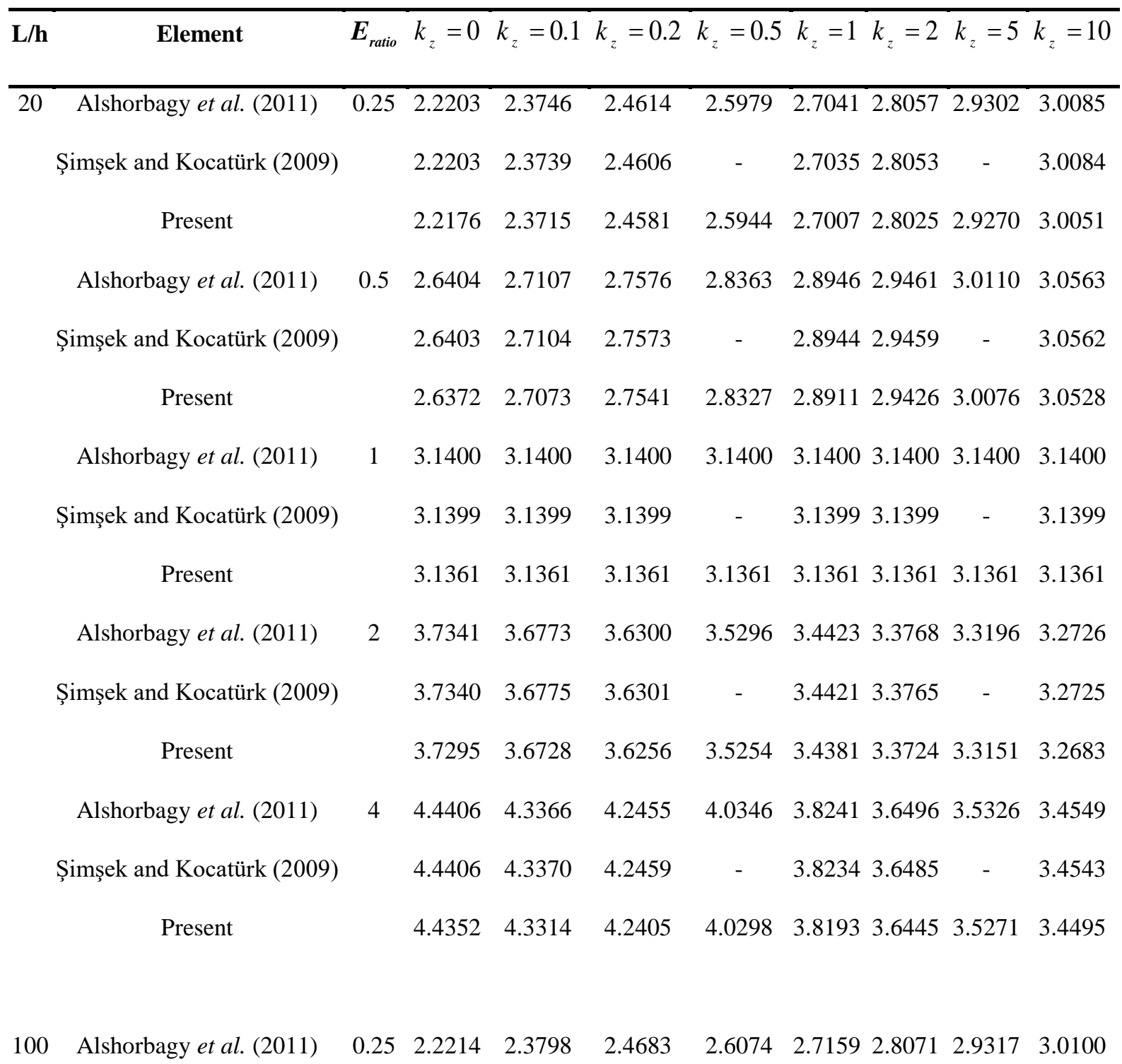




\begin{tabular}{|c|c|c|c|c|c|c|c|c|c|}
\hline Şimşek and Kocatürk (2009) & & 2.2213 & 2.3752 & 2.4621 & - & 2.7053 & 2.8071 & - & 3.0100 \\
\hline Present & & 2.2213 & 2.3757 & 2.4625 & 2.5990 & 2.7053 & 2.8070 & 2.9315 & 3.0099 \\
\hline Alshorbagy et al. (2011) & 0.5 & 2.6417 & 2.7121 & 2.7590 & 2.8377 & 2.8961 & 2.9476 & 3.0125 & 3.0578 \\
\hline Şimşek (2010) & & 2.6416 & 2.7117 & 2.7587 & - & 2.8960 & 2.9475 & - & 3.0578 \\
\hline Present & & 2.6416 & 2.7119 & 2.7589 & 2.8375 & 2.8959 & 2.9474 & 3.0124 & 3.0577 \\
\hline Alshorbagy et al. (2011) & 1 & 3.1415 & 3.1415 & 3.1415 & 3.1415 & 3.1415 & 3.1415 & 3.1415 & 3.1415 \\
\hline Şimşek and Kocatürk (2009) & & 3.1415 & 3.1415 & 3.1415 & - & 3.1415 & 3.1415 & - & 3.1415 \\
\hline Present & & 3.1414 & 3.1414 & 3.1414 & 3.1414 & 3.1414 & 3.1414 & 3.1414 & 3.1414 \\
\hline Alshorbagy et al. (2011) & 2 & 3.7359 & 3.6791 & 3.6317 & 3.5313 & 3.4440 & 3.3784 & 3.3213 & 3.274 \\
\hline Şimşek and Kocatürk (2009) & & 3.7359 & 3.6793 & 3.6320 & - & 3.4440 & 3.3784 & - & 3.2742 \\
\hline Present & & 3.7357 & 3.6789 & 3.6316 & 3.5312 & 3.4439 & 3.3782 & 3.3211 & 3.274 \\
\hline Alshorbagy et al. (2011) & 4 & 4.4428 & 4.3388 & 4.2476 & 4.0366 & 3.8260 & 3.6514 & 3.5343 & 3.456 \\
\hline Şimşek and Kocatürk (2009) & & 4.4427 & 4.3392 & 4.2481 & - & 3.8259 & 3.6513 & - & 3.456 \\
\hline Present & & 4.4426 & 4.3385 & 4.2474 & 4.0364 & 3.8258 & 3.6512 & 3.5341 & 3.456 \\
\hline
\end{tabular}

\section{Changing the material properties along the longitudinal direction}

In this section, the accuracy of the proposed element in free vibration and buckling analysis of FG beams is evaluated by varying the material properties along the longitudinal direction of the beam. It should be noted that the relation of the change of material properties along the length is given in Equation (18). The amount of material change along the longitudinal direction of the beam is also determined by the power parameter $k_{x}$.

In order to show the rapid convergence rate of the proposed element, first, an FGM beam with $l / h=5$ and $k_{x}=1$ is analyzed with different boundary conditions and by applying different meshes. The FGM beam is made of aluminum $(A l)$ material on the right and aluminum oxide $\left(A l_{2} \mathrm{O}_{3}\right)$ on the left. Table 7 shows the dimensionless natural frequency and buckling responses of the beam. Examination of this table demonstrates the high accuracy and rapid convergence rate of the proposed element.

Table 7. Convergence of the proposed element for FGM beam with different boundary conditions

$$
\left(l / h=5, k_{x}=1\right)
$$

\begin{tabular}{|c|c|c|}
\hline $\begin{array}{l}\text { Number of } \\
\text { Elements }\end{array}$ & C-C & P-P \\
\hline malized fund & frequency & $\bar{\omega}=\frac{\omega l^{2}}{h} \sqrt{\frac{\rho_{r}}{E_{r}}}$ \\
\hline
\end{tabular}

$2 \quad 8.5752 \quad 4.0428 \quad 1.7060$




\begin{tabular}{|c|c|c|c|}
\hline 4 & 8.0604 & 4.0043 & 1.5756 \\
\hline 6 & 7.9721 & 3.9985 & 1.5362 \\
\hline 8 & 7.9425 & 3.9966 & 1.5172 \\
\hline 10 & 7.9290 & 3.9957 & 1.5061 \\
\hline 12 & 7.9218 & 3.9953 & 1.4988 \\
\hline 14 & 7.9174 & 3.9950 & 1.4937 \\
\hline 16 & 7.9146 & 3.9948 & 1.4898 \\
\hline 18 & 7.9127 & 3.9947 & 1.4868 \\
\hline 20 & 7.9113 & 3.9946 & 1.4845 \\
\hline Normalized buckling lo & $\operatorname{pad}\left(\bar{N}_{c r}=\right.$ & $\left.{ }^{c r} \frac{12 l^{2}}{E_{r} h^{3}}\right)$ & \\
\hline 2 & 89.6356 & 24.8025 & 7.3949 \\
\hline 4 & 82.0847 & 24.6410 & 6.9238 \\
\hline 6 & 80.6285 & 24.6077 & 6.7884 \\
\hline 8 & 80.0885 & 24.5961 & 6.7232 \\
\hline 10 & 79.8359 & 24.5908 & 6.6848 \\
\hline 12 & 79.6982 & 24.5879 & 6.6594 \\
\hline 14 & 79.6150 & 24.5862 & 6.6414 \\
\hline 16 & 79.5609 & 24.5850 & 6.6280 \\
\hline 18 & 79.5239 & 24.5843 & 6.6176 \\
\hline 20 & 79.4973 & 24.5837 & 6.6092 \\
\hline
\end{tabular}

In order to further investigate such structures and study the effect of changing the material properties along its length, FGM beams are analyzed with different values of $k_{x}$. The dimensionless natural frequency and normalized buckling load of the beam with different boundary conditions are given in Figure 5. According to Figure 5 , as the aluminum beam progresses to oxidation, the natural frequency and critical buckling load of the beam increase. Also, the rate of increase will be the highest in the clamp-clamp beam mode and the lowest in the cantilever beam mode. 

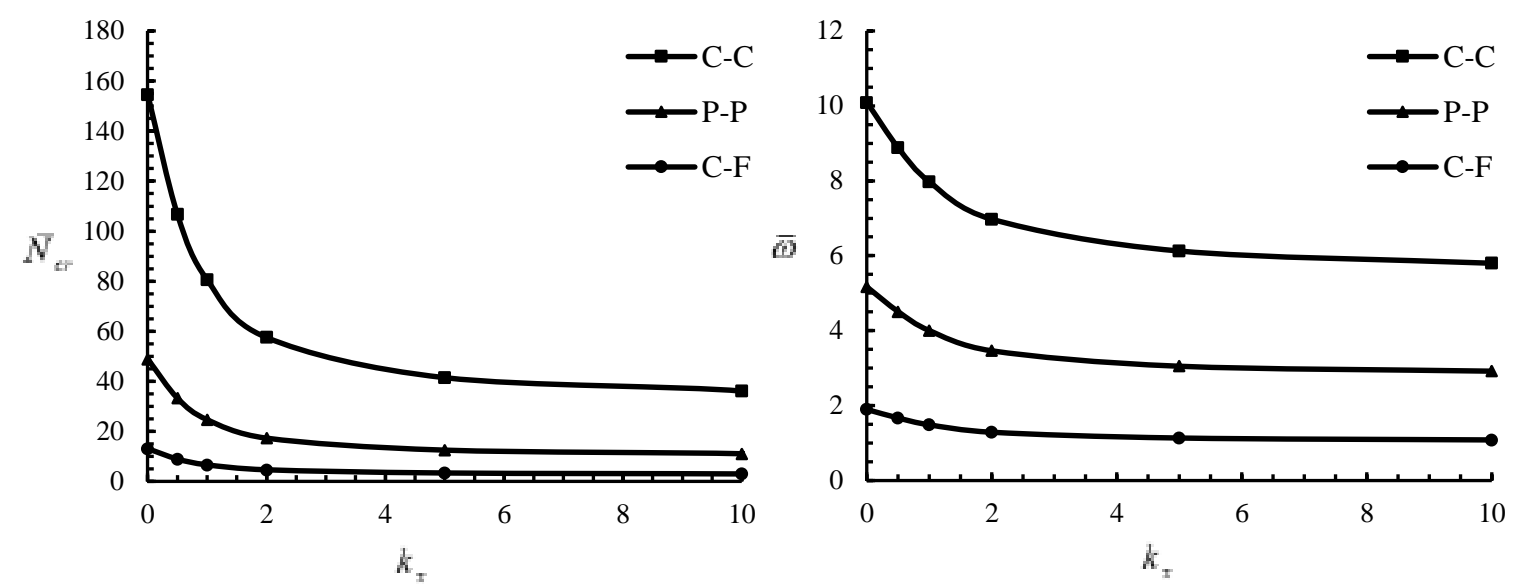

Figure 5. Influence of factor $k_{x}$ on dimensionless parameters $\bar{\omega}$ and $\bar{N}_{c r}$.

\section{Free vibration analysis for different elastic modulus ratios}

To investigate the effect of different elasticity modulus ratios on FGM beams, the free vibration of a simply supported beam is analyzed with length to thickness ratios 20 and 100. In this test, the elastic modulus ratios equal to $0.25,0.5,1,2$ are provided. Table 8 shows the dimensionless natural frequencies of the first, second, and third modes of the beam for each value of $k_{x}$.

Table 8. the first three non-dimensional natural frequencies of $\left(\lambda=\omega l^{2} \sqrt{\frac{\rho_{r} A}{E_{r} I}}\right)$ for FGM beam.

\begin{tabular}{|c|c|c|c|c|c|c|c|c|c|c|}
\hline $\mathbf{L} / \mathbf{h}$ & $E_{\text {ratio }}$ & $i$ & $k_{x}=0$ & $k_{x}=0.1$ & $k_{x}=0.2$ & $k_{x}=0.5$ & $k_{x}=1$ & $k_{x}=2$ & $k_{x}=5$ & $k_{x}=10$ \\
\hline \multirow[t]{13}{*}{20} & 0.25 & 1 & 2.2176 & 2.3380 & 2.4142 & 2.5593 & 2.7012 & 2.8513 & 3.0064 & 3.0717 \\
\hline & & 2 & 4.4127 & 4.6532 & 4.8055 & 5.0952 & 5.3772 & 5.6748 & 5.9821 & 6.1118 \\
\hline & & 3 & 6.5660 & 6.9258 & 7.1541 & 7.5871 & 8.0063 & 8.4466 & 8.9004 & 9.0927 \\
\hline & 0.5 & 1 & 2.6372 & 2.6921 & 2.7324 & 2.8131 & 2.8912 & 2.9728 & 3.0582 & 3.0959 \\
\hline & & 2 & 5.2476 & 5.3572 & 5.4377 & 5.5985 & 5.7539 & 5.9157 & 6.0850 & 6.1601 \\
\hline & & 3 & 7.8083 & 7.9720 & 8.0922 & 8.3322 & 8.5634 & 8.8030 & 9.0535 & 9.1650 \\
\hline & 1 & 1 & 3.1361 & 3.1361 & 3.1361 & 3.1361 & 3.1361 & 3.1361 & 3.1361 & 3.1361 \\
\hline & & 2 & 6.2405 & 6.2405 & 6.2405 & 6.2405 & 6.2405 & 6.2405 & 6.2405 & 6.2405 \\
\hline & & 3 & 9.2857 & 9.2857 & 9.2857 & 9.2857 & 9.2857 & 9.2857 & 9.2857 & 9.2857 \\
\hline & 2 & 1 & 3.7295 & 3.6849 & 3.6445 & 3.5458 & 3.4383 & 3.3320 & 3.2363 & 3.1947 \\
\hline & & 2 & 7.4213 & 7.3324 & 7.2519 & 7.0558 & 6.8426 & 6.6318 & 6.4413 & 6.3581 \\
\hline & & 3 & 11.0426 & 10.9102 & 10.7904 & 10.4994 & 10.1836 & 9.8714 & 9.5881 & 9.4633 \\
\hline & 4 & 1 & 4.4352 & 4.3535 & 4.2755 & 4.0691 & 3.8200 & 3.5602 & 3.3457 & 3.2659 \\
\hline
\end{tabular}




$\begin{array}{rrrrrrrrr}2 & 8.8254 & 8.6627 & 8.5076 & 8.0982 & 7.6045 & 7.0895 & 6.6627 & 6.5024 \\ 3 & 13.1320 & 12.8895 & 12.6589 & 12.0523 & 11.3226 & 10.5610 & 9.9258 & 9.6839\end{array}$

\begin{tabular}{|c|c|c|c|c|c|c|c|c|c|}
\hline \multirow[t]{3}{*}{0.25} & 1 & 2.2213 & 2.3418 & 2.4180 & 2.5633 & 2.7053 & 2.8557 & 3.0113 & 3.0768 \\
\hline & 2 & 4.4417 & 4.6831 & 4.8356 & 5.1260 & 5.4096 & 5.7097 & 6.0203 & 6.1515 \\
\hline & 3 & 6.6603 & 7.0234 & 7.2525 & 7.6877 & 8.1119 & 8.5604 & 9.0250 & 9.2221 \\
\hline \multirow[t]{3}{*}{0.5} & 1 & 2.6416 & 2.6966 & 2.7370 & 2.8177 & 2.8959 & 2.9776 & 3.0632 & 3.1011 \\
\hline & 2 & 5.2821 & 5.3922 & 5.4731 & 5.6344 & 5.7907 & 5.9537 & 6.1246 & 6.2003 \\
\hline & 3 & 7.9205 & 8.0862 & 8.2076 & 8.4495 & 8.6833 & 8.9267 & 9.1822 & 9.2961 \\
\hline \multirow[t]{3}{*}{1} & 1 & 3.1414 & 3.1414 & 3.1414 & 3.1414 & 3.1414 & 3.1414 & 3.1414 & 3.1414 \\
\hline & 2 & 6.2815 & 6.2815 & 6.2815 & 6.2815 & 6.2815 & 6.2815 & 6.2815 & 6.2815 \\
\hline & 3 & 9.4191 & 9.4191 & 9.4191 & 9.4191 & 9.4191 & 9.4191 & 9.4191 & 9.4191 \\
\hline \multirow[t]{3}{*}{2} & 1 & 3.7357 & 3.6911 & 3.6505 & 3.5516 & 3.4439 & 3.3374 & 3.2416 & 3.2000 \\
\hline & 2 & 7.4700 & 7.3805 & 7.2993 & 7.1015 & 6.8863 & 6.6739 & 6.4828 & 6.3995 \\
\hline & 3 & 11.2013 & 11.0667 & 10.9448 & 10.6481 & 10.3262 & 10.0089 & 9.7233 & 9.5982 \\
\hline \multirow[t]{3}{*}{4} & 1 & 4.4426 & 4.3607 & 4.2825 & 4.0757 & 3.8258 & 3.5654 & 3.3508 & 3.2710 \\
\hline & 2 & 8.8833 & 8.7194 & 8.5629 & 8.1492 & 7.6503 & 7.1306 & 6.7023 & 6.5428 \\
\hline & 3 & 13.3206 & 13.0741 & 12.8391 & 12.2188 & 11.4720 & 10.6952 & 10.0553 & 9.8161 \\
\hline
\end{tabular}

\section{CONCLUSION}

In this paper, a three-node element is proposed for the buckling and free vibration analysis of the FGM beams. For this purpose, the axial displacement and rotation fields of the second-order were chosen. Also, was utilized a third-order field for vertical displacements. By utilizing the Timoshenko theory and the assumption of constant shear strain in the element, some unknowns became available. Using other unknowns, element fields were written in terms of nodal degrees of freedom. Then, the formulations of the stiffness, mass, and geometrical stiffness matrices were calculated based on the elasticity modulus and density functions. The exponential variations of the elasticity modulus and density along the beam length and thickness were investigated separately. For better comparison, the answers of the good elements of the other researchers were available in each of these tests. The high accuracy and rapid convergence rate of responses in each of these modes for different boundary conditions, elastic modulus ratios, aspect ratio, and power-law exponents of FGM, prove the high efficiency of the proposed element.

\section{APPENDIX}

\section{Shape function matrix for proposed element+}




$$
\begin{aligned}
& \left\{\begin{array}{l}
u \\
\omega \\
\theta
\end{array}\right\}=\left[\begin{array}{ccccccc}
N_{u 1} & 0 & 0 & N_{u 2} & N_{u 3} & 0 & 0 \\
N_{\omega 1} & N_{\omega 2} & N_{\omega 3} & N_{\omega 4} & N_{\omega 5} & N_{\omega 6} & N_{\omega 7} \\
N_{\theta 1} & N_{\theta 2} & N_{\theta 3} & N_{\theta 4} & N_{\theta 5} & N_{\theta 6} & N_{\theta 7}
\end{array}\right]\left\{\begin{array}{lllllll}
u_{i} & \omega_{i} & \theta_{i} & u_{j} & u_{k} & \omega_{k} & \theta_{k}
\end{array}\right\}^{T} \\
& N_{u 1}=\frac{s}{2}(s-1), \quad N_{u 2}=1-s^{2}, \quad N_{u 3}=\frac{s}{2}(s+1) \\
& N_{\omega 1}=\frac{1}{4} l \lambda\left(s^{3}-s\right)\left(2 A_{12}-A_{11}\right), \quad N_{\omega 2}=\frac{1}{2}\left(\frac{1}{2}\left(s^{3}-3 s\right)+3 \lambda A_{22}\left(-s^{3}+s\right)+1\right) \\
& N_{\omega 3}=\frac{1}{8} l\left(2 \lambda\left(s^{3}-s\right)\left(A_{21}-3 A_{22}\right)+\left(s^{3}-s^{2}-s+1\right)\right), \quad N_{\omega 4}=l \lambda A_{12}\left(s-s^{3}\right) \\
& N_{\omega 5}=\frac{1}{4} l \lambda\left(s^{3}-s\right)\left(2 A_{12}+A_{11}\right), \quad N_{\omega 6}=-\frac{1}{2}\left(\frac{1}{2}\left(s^{3}-3 s\right)+3 \lambda A_{22}\left(-s^{3}+s\right)-1\right) \\
& N_{\omega 7}=\frac{1}{8} l\left(2 \lambda\left(s^{3}-s\right)\left(A_{21}-3 A_{22}\right)+\left(s^{3}+s^{2}-s-1\right)\right), \quad N_{\theta 1}=\frac{3}{2} \lambda\left(2 A_{12}\left(s^{2}-1\right)-A_{11}\left(s^{2}+1\right)\right) \\
& N_{\theta 2}=-\frac{3}{2 l}\left(6 \lambda A_{22}-1\right)\left(s^{2}-1\right), \quad N_{\theta 3}=\frac{3}{2} \lambda\left(s^{2}-1\right)\left(A_{21}-3 A_{22}\right)+\frac{1}{4}\left(3 s^{2}-2 s-1\right) \\
& N_{\theta 4}=6 \lambda A_{12}\left(1-s^{2}\right), \quad N_{\theta 5}=\frac{3}{2} \lambda\left(s^{2}-1\right)\left(2 A_{12}+A_{11}\right) \\
& N_{\theta 6}=\frac{3}{2 l}\left(6 \lambda A_{22}-1\right)\left(s^{2}-1\right), \quad N_{\theta 7}=-\frac{3}{2} \lambda\left(s^{2}-1\right)\left(A_{21}+3 A_{22}\right)+\frac{1}{4}\left(3 s^{2}+2 s-1\right)
\end{aligned}
$$

\section{REFERENCES}

Alshorbagy, A. E., Eltaher, M., \& Mahmoud, F. 2011. Free vibration characteristics of a functionally graded beam by finite element method. Applied Mathematical Modelling 35 (1):412-425.

Aria, A. I., Rabczuk, T., \& Friswell, M. I. 2019. A finite element model for the thermo-elastic analysis of functionally graded porous nanobeams. European Journal of Mechanics-A/Solids.

Barretta, R., Feo, L., Luciano, R., \& de Sciarra, F. M. 2015. Variational formulations for functionally graded nonlocal Bernoulli-Euler nanobeams. Composite Structures 129:80-89.

Barretta, R., Feo, L., Luciano, R., de Sciarra, F. M., \& Penna, R. 2016. Functionally graded Timoshenko nanobeams: a novel nonlocal gradient formulation. Composites Part B: Engineering 100:208-219.

Chakraborty, A., Gopalakrishnan, S., \& Reddy, J. 2003. A new beam finite element for the analysis of functionally graded materials. International Journal of Mechanical Sciences 45 (3):519-539.

Kadoli, R., Akhtar, K., \& Ganesan, N. 2008. Static analysis of functionally graded beams using higher order shear deformation theory. Applied Mathematical Modelling 32 (12):2509-2525.

Kahya, V., \& Turan, M. 2017. Finite element model for vibration and buckling of functionally graded beams based on the first-order shear deformation theory. Composites Part B: Engineering 109:108-115.

Kapuria, S., Bhattacharyya, M., \& Kumar, A. 2008. Bending and free vibration response of layered functionally graded beams: a theoretical model and its experimental validation. Composite Structures 82 (3):390-402.

Li, S.-R., \& Batra, R. C. 2013. Relations between buckling loads of functionally graded Timoshenko and homogeneous Euler-Bernoulli beams. Composite Structures 95:5-9. 
Li, W., Ma, H., \& Gao, W. 2019. A higher-order shear deformable mixed beam element model for accurate analysis of functionally graded sandwich beams. Composite Structures 221:110830.

Li, X.-F. 2008. A unified approach for analyzing static and dynamic behaviors of functionally graded Timoshenko and Euler-Bernoulli beams. Journal of sound and vibration 318 (4-5):1210-1229.

Nguyen, D. K., Nguyen, Q. H., Tran, T. T., \& Bui, V. T. 2017. Vibration of bi-dimensional functionally graded Timoshenko beams excited by a moving load. Acta Mechanica 228 (1):141-155.

Nguyen, H. N., Hong, T. T., Vinh, P. V., \& Thom, D. V. 2019. An Efficient Beam Element Based on Quasi-3D Theory for Static Bending Analysis of Functionally Graded Beams. Materials 12 (13):2198.

Nguyen, T.-K., Nguyen, T. T.-P., Vo, T. P., \& Thai, H.-T. 2015. Vibration and buckling analysis of functionally graded sandwich beams by a new higher-order shear deformation theory. Composites Part B: Engineering 76:273285.

Nguyen, T.-K., Vo, T. P., \& Thai, H.-T. 2013. Static and free vibration of axially loaded functionally graded beams based on the first-order shear deformation theory. Composites Part B: Engineering 55:147-157.

Sankar, B. V. 2001. An elasticity solution for functionally graded beams. Composites Science and Technology 61 (5):689-696.

Şimşek, M. 2010. Fundamental frequency analysis of functionally graded beams by using different higher-order beam theories. Nuclear Engineering and Design 240 (4):697-705.

Şimşek, M., \& Kocatürk, T. 2009. Free and forced vibration of a functionally graded beam subjected to a concentrated moving harmonic load. Composite Structures 90 (4):465-473.

Sina, S., Navazi, H., \& Haddadpour, H. 2009. An analytical method for free vibration analysis of functionally graded beams. Materials \& Design 30 (3):741-747.

Soltani, M., Asgarian, B., \& Mohri, F. 2019. Improved finite element model for lateral stability analysis of axially functionally graded non-prismatic I-beams. International Journal of Structural Stability and Dynamics.

Yaghoobi, M., \& Koochi, A. 2021. Electromagnetic instability analysis of functionally graded tapered nanotweezers. Physica Scripta 96 (8):085701.

Yaghoobi, M., Sedaghatjo, M., Alizadeh, R., \& Karkon, M. 2021. Evaluating the Effect of Asymmetric Crosssection in Free Vibration and Bending Analysis Results of FG Sandwich Beam by Proposing Simple Efficient Element. Periodica Polytechnica Civil Engineering 65 (2):638-648. 